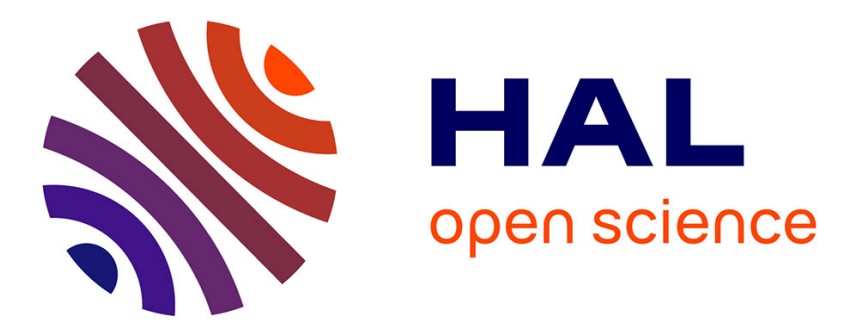

\title{
Electrosynthesis of polypyrrole nano/micro structures using an electrogenerated oriented polypyrrole nanowire array as framework
}

Catherine Debiemme-Chouvy, Ahmed Fakhry, Françoise Pillier

\section{- To cite this version:}

Catherine Debiemme-Chouvy, Ahmed Fakhry, Françoise Pillier. Electrosynthesis of polypyrrole nano/micro structures using an electrogenerated oriented polypyrrole nanowire array as framework. Electrochimica Acta, 2018, 268, pp.66 - 72. 10.1016/j.electacta.2018.02.092 . hal-01745694

\section{HAL Id: hal-01745694 \\ https: / hal.sorbonne-universite.fr/hal-01745694}

Submitted on 28 Mar 2018

HAL is a multi-disciplinary open access archive for the deposit and dissemination of scientific research documents, whether they are published or not. The documents may come from teaching and research institutions in France or abroad, or from public or private research centers.
L'archive ouverte pluridisciplinaire HAL, est destinée au dépôt et à la diffusion de documents scientifiques de niveau recherche, publiés ou non, émanant des établissements d'enseignement et de recherche français ou étrangers, des laboratoires publics ou privés. 


\title{
Electrosynthesis of polypyrrole nano/micro structures using an electrogenerated
} oriented polypyrrole nanowire array as framework.

\author{
Catherine Debiemme-Chouvy ${ }^{*}$, Ahmed Fakhry, Françoise Pillier, \\ Laboratoire Interfaces et Systèmes Electrochimiques, LISE UMR 8235, Sorbonne Universités, \\ UPMC Univ Paris 06, CNRS, 4 place Jussieu, F-75005 Paris, France.
}

\begin{abstract}
The purpose of this paper is to show that it is possible to increase the diameter and the-length of the nanostructures of a framework formed of oriented polypyrrole nanowires that has been prepared by a templateless electrochemical method based on the use of a pyrrole solution containing a high concentration of weak-acid anion and a low concentration of non-acidic anion. The dimensions of the initial nanowires are increased by performing an additional electrosynthesis in a 'classical' monomer solution. Depending on the polarization time of this last synthesis (a few tens of seconds), wires with various diameters, from one hundred up to several hundred nanometers, are obtained. In addition to the variation of the nanowire size, these findings confirm, as outlined in the reaction mechanism we have proposed, that the base of the nanowires is surrounded by a thin non-conductive polymer i.e. by an overoxidized polypyrrole film. Actually this paper shows a proof-of-concept. Indeed one can imagine that the second polymeric electrodeposit could be performed using an organic monomer solution, using functionalized pyrrole monomer to fabricate a biosensor having large specific area, and/or using anions which could be drugs.
\end{abstract}

\section{Keywords}

Polypyrrole, nanostructures, nanowire, microstructure, electrochemical synthesis

\footnotetext{
*Corresponding author. Email: catherine.debiemme-chouvy@upmc.fr
} 


\section{Introduction}

Polypyrrole (PPy) is one of the most widely used conducting polymers, because of its numerous advantages such as its biocompatibility, environmental stability or ease of preparation even under nanostructured form. Polypyrrole nanostructures are generally synthesized either by a chemical or by an electrochemical route using soft or hard templates [1-11] or sacrificial oxidative templates such as $\mathrm{MnO}_{2}$ [12-15]. For instance, PPy nanotubes can be synthesized by using a self-degraded methyl orange (MO) template method [16-19]. However It has also been established that polypyrrole nanostructures can alse be prepared without the use of any template [20-24]. Notably In that respect, in our previous works [2527], we brought to light that different polypyrrole nanostructures can be synthesized by using a one-step electrochemical synthesis, without using any template. Indeed, nanostructured polypyrrole films, which are superhydrophilic, are electrogenerated in the presence of (i) a high concentration of weak-acid anions conferring to upon the monomer solution a $\mathrm{pH}$ between 6 and 10, and (ii) a low concentration of non-acidic anions such as perchlorate ions. Notably, Depending on the perchlorate concentration of a $0.15 \mathrm{M}$ pyrrole solution containing 0.2 M monohydrogenophosphate, different PPy nanostructures can be synthesized. In the absence or in the presence of a very low concentration of perchlorate ions $\left(<10^{-4} \mathrm{M}\right)$, an ultrathin non-conductive overoxidized PPy (OPPy) film is obtained [28, 29]. This finding was notably determined in particular by XPS analyses [28] and EIS studies [29]. Notice that due to its compactness, this OPPy film prevents the diffusion to the electrode surface of large redox species such as ascorbic acid and dopamine [30] or $\mathrm{Fe}(\mathrm{CN})_{6}{ }^{4-}$ and $\mathrm{Ru}\left(\mathrm{NH}_{3}\right)_{6}{ }^{2+}[31]$ avoiding their electro-oxidation. It is not the case for-On the contrary, small molecules such as $\mathrm{H}_{2} \mathrm{O}_{2}$ and $\mathrm{H}_{2} \mathrm{O}$ can diffuse across this OPPy film, and therefore be oxidized at the electrode surface $[30,31]$. In the presence of a higher concentration of perchlorate ions $\left(>10^{-4} \mathrm{M}\right)$, an oriented nanowire (NW) array or a network of more or less interconnected nanofibers is formed [26]. 
The oxidation of pyrrole (Py) leads to the formation of polypyrrole under its oxidized form, doped with anions (A'), according to the following reaction $[32,33]$ :

$$
n \mathrm{Py}+\gamma \mathrm{nA}^{-} \rightarrow\left[(\mathrm{Py})_{n}^{(\gamma n)+}, \gamma \mathrm{n} \mathrm{A}^{-}\right]+2(\mathrm{n}-1) \mathrm{H}^{+}+((2+\gamma) \mathrm{n}-2) \mathrm{e}^{-}
$$

where $\gamma$ stands for the doping level of the polymer, it is generally in the range of 0.25 to 0.33 $[34,35]$.

In the presence of weak-acid anions, the protons released during Py oxidation (reaction (1)) are captured by these anions:

$$
\mathrm{A}^{-}+\mathrm{H}^{+} \rightarrow \mathrm{AH}
$$

The mechanism that we have previously proposed in order to explain the formation of a nanostructured polypyrrole film is summarized in Figure 1. It is based on the variation of the interfacial concentration of anions. Indeed, during pyrrole oxidation protons are released during pyrrole oxidation, and collected by the weak-acid anions present in the solution (reaction (2)), which results in a drastic decrease, or elimination, of anions at the electrode/solution interface. As pyrrole oxidation requires the presence of anions (reaction (1)), which are no longer available, this reaction cannot occur anymore. Instead, water oxidation takes place, leading to the formation of hydroxyl radicals. These radicals can either react with the already formed polypyrrole film, resulting in its overoxidation [36], or with themselves, leading to the formation of $\mathrm{H}_{2} \mathrm{O}_{2}$ molecules. These molecules are subsequently oxidized into $\mathrm{O}_{2}$ molecules that form nanobubbles inside the polymer, protecting it against the hydroxyl radical action and therefore preventing locally its overoxidation allowing the conservation of some conductive zones (step 2 in Fig. 1). After bubbles evolution, the electrooxidation of the monomers takes place at these zones, leading to the formation of nanorods/nanowires (step (3) in Figure 1). Obviously, the diameter of these PPy nanostructures depends on the size of the $\mathrm{O}_{2}$ bubbles. Notice that this process differs from the 


\section{ACCEPTED MANUSCRIPT}

one involving gas bubbles as template for PPy microstructure electrosynthesis [37-39].

Therefore, the nature of the anions present in the monomer solution and the release of protons during Py electropolymerization are the two main parameters involved in polypyrrole nanostructure formation. Under potentiostatic conditions, using a Pt anode, the diameter of the PPy nanowires is about $80 \mathrm{~nm}$ and their length depends on the electrode polarization time [25]. It has been shown that PPy nanostructures are also electrogenerated in the presence of a low monomer concentration and a high non-acidic anion concentration [26].

The oriented PPy nanowire array could be used as framework for the growth of larger and longer nano/micro structures. Therefore, a second electrosynthesis could be done, using for example functionalized monomer in order to prepare a biosensor [40-46], or using organic solvent containing anions which could be drugs [47-50].

The aim of the present work is to show that it is possible to vary the diameter and the length of oriented polypyrrole nanowires by performing an additional electrosynthesis in a classical pyrrole solution. Moreover, it allows to confirm provides confirmation that the nanowire base is surrounded by an overoxidized polypyrrole (non-conductive polymer) layer. These experiments also allow us to determine whether or not the polypyrrole nanowires are conductive over their entire surface (top and sides). Therefore, the strategy developed in the present work involves two steps. The first one requires is the electrogeneration of oriented nanowires, which requires the use of a monomer solution containing a high concentration of weak-acid anions and a low concentration of perchlorates. The second step is based on implies an anodic polarization in a classical monomer solution, without any weak-acid anions.

\section{Experimental}

The polypyrrole films were synthesized using preliminarily distilled pyrrole. All the solutions were prepared with bi-distilled water. $\mathrm{Py}, \mathrm{K}_{2} \mathrm{HPO}_{4}, \mathrm{KCH}_{3} \mathrm{COO}, \mathrm{K}_{2} \mathrm{CO}_{3}$ and $\mathrm{LiClO}_{4}$ were purchased from Aldrich. 
The electrochemical experiments were performed in a classical three-electrode electrochemical cell. A platinum foil was used as counter electrode and a saturated calomel electrode (SCE) was used as the reference electrode. A double junction was used in order to avoid chloride diffusion into the Py solution. The working electrode was a Pt electrode ( $\mathrm{S}=$ $0.07 \mathrm{~cm}^{2}$ ) for electrochemical studies and Au/mica substrate for SEM observations. The preparation of the substrates was the following: a thin gold film $(\sim 80 \mathrm{~nm})$ was deposited under low pressure $\left(10^{-4} \mathrm{~Pa}\right)$ by thermal evaporation on a mica substrate.

All the electrosyntheses were performed under potentiostatic conditions, in $0.15 \mathrm{M} \mathrm{Py}+0.2$ $\mathrm{M} \mathrm{K}_{2} \mathrm{HPO}_{4}+10^{-3} \mathrm{M} \mathrm{LiClO}_{4}$ for the first synthesis and in $0.15 \mathrm{M} \mathrm{Py}+0.2 \mathrm{M} \mathrm{LiClO}_{4}$ for the second one, during given times named $\mathrm{t}_{1}$ and $\mathrm{t}_{2}$, respectively. The $\mathrm{pH}$ of the first monomer solution is 8.9 .

The superhydrophilic character of the PPy films was checked by a drop test experiment: a small pure water droplet is deposited onto the film and the spreading of the drop is analyzed. When the film is nanostructured the drop spreads out whereas it does not for classical cauliflower-like films.

As far as the electropolymerization of Py is concerned, an Autolab PGSTAT30 potentiostat (Ecochemie) controlled with the GPES software was employed. The film morphology was examined under a field emission gun scanning electron microscope (FEG-SEM), Ultra55 Zeiss, operating at $5 \mathrm{kV}$.

\section{Results and discussion}

Firstly, the framework composed of oriented PPy nanowires was synthesized by performing an electropolymerization of pyrrole monomers under potentiostatic conditions at $0.75 \mathrm{~V} / \mathrm{SCE}$ in a solution composed of $0.15 \mathrm{M}$ pyrrole, $0.2 \mathrm{M} \mathrm{K}_{2} \mathrm{HPO}_{4}$ and $10^{-3} \mathrm{M} \mathrm{LiClO}_{4}$ (see the SEM micrograph in Fig. 1). The average diameter of the nanowires is about $80 \mathrm{~nm}$. Notice that the framework can also be obtained using acetate or carbonate instead of 
monohydrogenophosphate. Indeed by replacing $\mathrm{HPO}_{4}{ }^{2-}$ by $\mathrm{CO}_{3}{ }^{2-}$ or $\mathrm{CH}_{3} \mathrm{COO}^{-}$, we have obtained the same results i.e. nanostructured PPy films (see Table 1). Then, another polypyrrole deposit was performed onto these nanostructures. This second electrosynthesis was conducted in a monomer solution containing only perchlorates as anions, solution which generally leads to the formation of a PPy film with cauliflower-like structure.

Figures $2 \mathrm{~A}$ and $2 \mathrm{~B}$ (curves (a)) show the anodic current versus time responses for the first and second synthesis, respectively ( 5 experiments: $t_{1}=200 \mathrm{~s}, \mathrm{t}_{2}=30,60,90180$ or $\left.300 \mathrm{~s}\right)$. For comparison, the curve recorded at a bare $\mathrm{Pt}$ electrode, in the experimental conditions employed for the second synthesis, is also depicted in Fig. 2B (curve (b)). The shape of the I(t) curves and the total anodic charge (Fig. 3) clearly depend on the experimental conditions. After the second electrosynthesis, if the deposition times are longer than 90 seconds, the PPy films are no more superhydrophilic i.e. no more nanostructured. As previously stated, curves (a) and (b) in Fig. 2B correspond to the two-step and to the one-step 300 second synthesis, respectively. The shape of these $\mathrm{I}(\mathrm{t})$ responses differs regarding the 90 first seconds, which is consistent with the fact that the substrates are not the same (NW-PPy/Pt and bare Pt). After this period (90 s), (a) and (b) curves are parallel in good agreement with the cauliflower structure obtained when the second synthesis lasts more than $90 \mathrm{~s}$ (at $0.75 \mathrm{~V} / \mathrm{SCE}$ ) (see below).

The anodic charges $(\mathrm{Q})$ versus the electrode polarization time are plotted in Figure 3. In this figure, the black open squares indicate the PPy films which are superhydrophilic i.e. which are nanostructured. With regard to the second synthesis (green squares), the $\mathrm{Q}(\mathrm{t})$ relationship is linear. One can notice that when the polarization lasts $300 \mathrm{~s}$, the charge passed during the second synthesis is about $20 \%$ higher than those recorded in the same conditions but using a bare Pt electrode, $215 \mathrm{mC}$ and $177 \mathrm{mC}$ respectively, in good agreement with the initial real surface of the electrode (3D / 2D). 
Some of these polypyrrole films have been observed by SEM. In Figure 4 are reported micrographs obtained for a Au/mica substrate first polarized during $600 \mathrm{~s}$ and then only a part of its surface has undergone a second polarization of 50 seconds in the 'classical' Py solution. Micrograph A shows the film after the first polarization whereas micrographs B-D show the film after the second polarization. Notice that micrographs A and B were done at the same magnitude. From these micrographs, it is clear that the growth of the polymer occurs on the whole surface of the nanowires, since their diameter increases from $80 \mathrm{~nm}$ to $200 \mathrm{~nm}$ and their length increases from $500 \mathrm{~nm}$ [25] up to $1500 \mathrm{~nm}$. Besides, the SEM micrographs presented in Figure 5 show different kinds of (nano)structures depending on the second synthesis duration, the first synthesis duration being 200 s. When the second polarization duration increases, the polypyrrole nanowire diameter increases too. Finally, for 300 seconds of polymerization, the PPy film has a cauliflower-like structure (see micrographs E and F in Fig. 5) because during the electrode polarization the diameter of the nanowires has so increased that their coalescence has occurred.

The diameter and the length of the polypyrrole nanostructures obtained after the second synthesis versus the polymerization duration are plotted in Figure 6. The nanowire diameter increases with the second polarization time, leading to a decrease of the space between the nanowires until they coalesce and form a $2 \mathrm{D}$ film that is no more superhydrophilic, confirming

that the PPy film is no longer nanostructured. Before coalescence, the growth rate in terms of fiber length is about $17 \mathrm{~nm} \mathrm{~s}^{-1}$, which is almost 20 times faster than the rate determined with the Py solution used for the framework synthesis (first synthesis) [25]. This finding could be explained by the fact that the Py electropolymerization is limited by the concentration of the anions present at the electrode/solution interface [51]. Finally, a series of PPy framework was prepared by varying the polarization durations $\left(\mathrm{t}_{1}\right)$, leading to different anodic charges $\left(\mathrm{Q}_{1}\right)$. A second polarization, lasting a given time $\left(t_{2}=10,15,20,30,40\right.$ or 50 seconds), was then 
performed in the 'classical' Py solution (solution containing only perchlorates as anions). The anodic charges after the second synthesis $\left(\mathrm{Q}_{2}\right)$ vs. anodic charges after the first synthesis $\left(\mathrm{Q}_{1}\right)$ are plotted in Fig. 7A. As it can be noticed from this figure, for a given $t_{2}$, the relationship between $\mathrm{Q}_{1}$ and $\mathrm{Q}_{2}$ is linear and does not pass through the origin:

$$
\mathrm{Q}_{2}=\alpha+\beta \mathrm{Q}_{1}
$$

Whatever $\mathrm{t}_{1}$ is, the first synthesis leads to PPy nanowire arrays having the same NW density and the same NW diameter, as these parameters only depend on the nature of the electrode, the applied potential, and the Py solution composition. Therefore, the variation of $\mathrm{t}_{1}$ i.e. $\mathrm{Q}_{1}$ only leads to the variation of the PPy nanowire length [25]. As the relationship between the charge passed during the second synthesis and the one passed during the first synthesis (which determines the length of the wires) is linear, one can conclude that the Py polymerization takes place on the entire surface of the nanowires and not only on their top. In this latter case, $\mathrm{Q}_{2}$ should be independent of the wire length i.e. of $\mathrm{Q}_{1}$. This conclusion is in good agreement with the SEM observations (Figs. 4, 5, 6).

$\alpha$ and $\beta$ parameters of equation (3) versus the polarization time of the second synthesis are depicted in Figures 7B and 7C, respectively. These relationships are linear. $\mathrm{Q}_{2}$ corresponds to Py oxidation that leads to the generation of PPy at a place that can be divided into three zones, named a, b, and c in Figure 8.

$$
\mathrm{Q}_{2}=\mathrm{Q}_{\mathrm{a}}+\mathrm{Q}_{\mathrm{b}}+\mathrm{Q}_{\mathrm{c}}
$$

As it can be noticed from Figure 8, zone a corresponds to the enlargement of the nanowires. Therefore, $\mathrm{Q}_{\mathrm{a}}$ is function of $\mathrm{Q}_{1}$. Zones $\mathrm{b}$ and c correspond to the elongation of the nanowires and the enlargement of the nanowires formed during the second synthesis, respectively. Therefore both $\mathrm{Q}_{\mathrm{b}}$ and $\mathrm{Q}_{\mathrm{c}}$ are independent from $\mathrm{Q}_{1}$, which sets the length of the nanowire. $\alpha$ is proportional to $t_{2}$ as evidenced by Fig. 7B, in good agreement with Fig. 6.

Consequently, taking into account that $\alpha=Q_{b}+Q_{c}$ and $\beta=a t_{2}$, the combination of equations (3) and (4) gives 


\section{ACCEPTED MANUSCRIPT \\ $\mathrm{Q}_{2}=\mathrm{Q}_{\mathrm{b}}+\mathrm{Q}_{\mathrm{c}}+\mathrm{a} \mathrm{t}_{2} \mathrm{Q}_{1}$

All these findings allow us to confirm that the PPy nanowires of the framework (first synthesis) are conductive on their entire surface i.e. on their top and their sides, as it is possible to deposit another polypyrrole film all around the nanostructures whose diameter increases with the polarization time of the second synthesis (Fig. 6). Moreover, these findings confirm that the layer which surrounds the nanowire base is non-conductive i.e. it is an overoxidized PPy film, as shown in the mechanism proposed in our previous work regarding the formation of the different polypyrrole nanostructures (see Fig. 1).

\section{Conclusions}

It is possible to use oriented polypyrrole nanowires obtained by a one-step templateless electrochemical method as framework to perform a second synthesis in a pyrrole solution that does not contain a high concentration of weak-acid anions. Depending on the polarization duration of this synthesis, the diameter of the nanowires varies from a few tens of nanometers up to several hundred nanometers, and after a threshold of polarization time cauliflower-like structures are obtained. These findings are important because they allow us to confirm the global mechanism we proposed to achieve the electrogeneration of PPy nanostructure without the use of any template, just by using a monomer solution containing a high concentration of weak-acidic anions having $\mathrm{pKa}>6$. Finally, this paper shows a proof-of-concept, indeed one can imagine that the second electrodeposit could be performed using functionalized pyrrole monomer to fabricate electrochemical biosensors with large specific area, for example or using an organic solvent, and/or using anions which could be drugs. 


\section{REFERENCES}

[1] A. Malinauskas, J. Malinauskiene, A. Ramanavicius, Conducting polymer-based nanostructurized materials: electrochemical aspects, Nanotechnology 16(10) (2005) R51-R62. [2] Z. Yin, Q. Zheng, Controlled Synthesis and Energy Applications of One-Dimensional Conducting Polymer Nanostructures: An Overview, Advanced Energy Materials 2(2) (2012) 179-218.

[3] H.D. Tran, D. Li, R.B. Kaner, One-Dimensional Conducting Polymer Nanostructures: Bulk Synthesis and Applications, Advanced Materials 21(14-15) (2009) 1487-1499.

[4] J. Heinze, B.A. Frontana-Uribe, S. Ludwigs, Electrochemistry of Conducting PolymersPersistent Models and New Concepts, Chemical Reviews 110(8) (2010) 4724-4771.

[5] Y.Z. Long, M.M. Li, C.Z. Gu, M.X. Wan, J.L. Duvail, Z.W. Liu, Z.Y. Fan, Recent advances in synthesis, physical properties and applications of conducting polymer nanotubes and nanofibers, Progress in Polymer Science 36(10) (2011) 1415-1442.

[6] J.I. Lee, S.H. Cho, S.M. Park, J.K. Kim, J.W. Yu, Y.C. Kim, T.P. Russell, Highly aligned ultrahigh density arrays of conducting polymer nanorods using block copolymer templates, Nano Letters 8(8) (2008) 2315-2320.

[7] L. Piraux, V.A. Antohe, E. Ferain, D. Lahem, Self-supported three-dimensionally interconnected polypyrrole nanotubes and nanowires for highly sensitive chemiresistive gas sensing, Rsc Advances 6(26) (2016) 21808-21813.

[8] C. Li, H. Bai, G.Q. Shi, Conducting polymer nanomaterials: electrosynthesis and applications, Chemical Society Reviews 38(8) (2009) 2397-2409.

[9] G.W. Lu, C. Li, G.Q. Shi, Polypyrrole micro- and nanowires synthesized by electrochemical polymerization of pyrrole in the aqueous solutions of pyrenesulfonic acid, Polymer 47(6) (2006) 1778-1784.

[10] C. Shen, Y.P. Sun, W. Yao, Y. Lu, Facile synthesis of polypyrrole nanospheres and their carbonized products for potential application in high-performance supercapacitors, Polymer 55(12) (2014) 2817-2824.

[11] J.L. Duvail, S. Dubois, S. Demoustier-Champagne, Y. Long, L. Piraux, Physical properties of magnetic metallic nanowires and conjugated polymer nanowires and nanotubes, International Journal of Nanotechnology 5(6-8) (2008) 838-850.

[12] J. Zhang, X.H. Liu, L.X. Zhang, B.Q. Cao, S.H. Wu, Reactive Template Synthesis of Polypyrrole Nanotubes for Fabricating Metal/Conducting Polymer Nanocomposites, Macromolecular Rapid Communications 34(6) (2013) 528-532.

[13] L. Benhaddad, M.C. Bernard, C. Deslouis, L. Makhloufi, B. Messaoudi, A. Pailleret, H. Takenouti, Chemical synthesis of hollow sea urchin like nanostructured polypyrrole particles through a core-shell redox mechanism using a $\mathrm{MnO} 2$ powder as oxidizing agent and sacrificial nanostructured template, Synthetic Metals 175 (2013) 192-199.

[14] J.G. Wang, B.Q. Wei, F.Y. Kang, Facile synthesis of hierarchical conducting polypyrrole nanostructures via a reactive template of $\mathrm{MnO} 2$ and their application in supercapacitors, Rsc Advances 4(1) (2014) 199-202.

[15] D.P. Dubal, Z. Caban-Huertas, R. Holze, P. Gomez-Romero, Growth of polypyrrole nanostructures through reactive templates for energy storage applications, Electrochimica Acta 191 (2016) 346-354.

[16] X.M. Yang, Z.X. Zhu, T.Y. Dai, Y. Lu, Facile fabrication of functional polypyrrole nanotubes via a reactive self-degraded template, Macromolecular Rapid Communications 26(21) (2005) 1736-1740.

[17] X.M. Yang, T.Y. Dai, Z.X. Zhu, Y. Lu, Electrochemical synthesis of functional polypyrrole nanotubes via a self-assembly process, Polymer 48(14) (2007) 4021-4027.

[18] I. Sapurina, Y. Li, E. Alekseeva, P. Bober, M. Trchova, Z. Moravkova, J. Stejskal, Polypyrrole nanotubes: The tuning of morphology and conductivity, Polymer 113 (2017) 247 258. 
[19] J. Kopecka, D. Kopecky, M. Vrnata, P. Fitl, J. Stejskal, M. Trchova, P. Bober, Z. Moravkova, J. Prokes, I. Sapurina, Polypyrrole nanotubes: mechanism of formation, Rsc Advances 4(4) (2014) 1551-1558.

[20] C. Debiemme-Chouvy, Nanostructured polypyrrole materials: Focus on templateless synthetic methods and on some applications., in: M. Chehimi, J. Pinson (Eds.), Applied surface chemistry of nanomaterials, Nova Science Publichers, New York, 2013, pp. 257-278. [21] I.S. Chronakis, S. Grapenson, A. Jakob, Conductive polypyrrole nanofibers via electrospinning: Electrical and morphological properties, Polymer 47(5) (2006) 1597-1603.

[22] H.D. Tran, K. Shin, W.G. Hong, J.M. D'Arcy, R.W. Kojima, B.H. Weiller, R.B. Kaner, A template-free route to polypyrrole nanofibers, Macromolecular Rapid Communications 28(24) (2007) 2289-2293.

[23] A. Turco, E. Mazzotta, C. Di Franco, M.V. Santacroce, G. Scamarcio, A.G. Monteduro, E. Primiceri, C. Malitesta, Templateless synthesis of polypyrrole nanowires by non-static solution-surface electropolymerization, Journal of Solid State Electrochemistry 20(8) (2016) 2143-2151.

[24] H.D. Tran, Y. Wang, J.M. D'Arcy, R.B. Kaner, Toward an understanding of the formation of conducting polymer nanofibers, Acs Nano 2(9) (2008) 1841-1848.

[25] C. Debiemme-Chouvy, Template-free one-step electrochemical formation of polypyrrole nanowire array, Electrochemistry Communications 11(2) (2009) 298-301.

[26] A. Fakhry, F. Pillier, C. Debiemme-Chouvy, Templateless electrogeneration of polypyrrole nanostructures: impact of the anionic composition and $\mathrm{pH}$ of the monomer solution, Journal of Materials Chemistry A 2(25) (2014) 9859-9865.

[27] A. Fakhry, H. Cachet, C. Debiemme-Chouvy, Mechanism of formation of templateless electrogenerated polypyrrole nanostructures, Electrochimica Acta 179 (2015) 297-303.

[28] C. Debiemme-Chouvy, One-step electrochemical synthesis of a very thin overoxidized polypyrrole film, Electrochemical and Solid State Letters 10(12) (2007) E24-E26.

[29] A. Fakhry, H. Cachet, C. Debiemme-Chouvy, Electrochemical Characterisations of Ultra Thin Overoxidized Polypyrrole Films Obtained by One-Step Electrosynthesis, Journal of the Electrochemical Society 160(10) (2013) D465-D470.

[30] C. Debiemme-Chouvy, A very thin overoxidized polypyrrole membrane as coating for fast time response and selective $\mathrm{H}_{2} \mathrm{O}_{2}$ amperometric sensor, Biosensors \& Bioelectronics 25(11) (2010) 2454-2457.

[31] C. Debiemme-Chouvy, M. Gallois, Characterization of a very thin overoxidized polypyrrole membrane: application to $\mathrm{H}_{2} \mathrm{O}_{2}$ determination, Surface and Interface Analysis 42(6-7) (2010) 1144-1147.

[32] E.M. Genies, G. Bidan, A.F. Diaz, Spectroelectrochemical study of polypyrrole films, Journal of Electroanalytical Chemistry 149(1-2) (1983) 101-113.

[33] Y.J. Qiu, J.R. Reynolds, Electrochemically initiated chain polymerization of pyrrole in aqueous-media, Journal of Polymer Science Part a-Polymer Chemistry 30(7) (1992) 13151325.

[34] A. Diaz, Electrochemical preparation and characterization of conducting polymers, Chemica Scripta 17(1-5) (1981) 145-148.

[35] M. Salmon, A.F. Diaz, A.J. Logan, M. Krounbi, J. Bargon, Chemical modification of conducting polypyrrole films, Molecular Crystals and Liquid Crystals 83(1-4) (1982) 1297 1308.

[36] C. Debiemme-Chouvy, T.T.M. Tran, An insight into the overoxidation of polypyrrole materials, Electrochemistry Communications 10(6) (2008) 947-950.

[37] L.T. Qu, G.Q. Shi, J.Y. Yuan, G.Y. Han, F. Chen, Preparation of polypyrrole microstructures by direct electrochemical oxidation of pyrrole in an aqueous solution of camphorsulfonic acid, Journal of Electroanalytical Chemistry 561(1-2) (2004) 149-156. 
[38] M. Mazur, A. Frydrychewicz, Polymerization at the Gas/Solution interface: Preparation of polymer microstructures with gas bubbles as templates, Journal of Applied Polymer Science 106(4) (2007) 2169-2176.

[39] B. Parakhonskiy, D. Shchukin, Polypyrrole Microcontainers: Electrochemical Synthesis and Characterization, Langmuir 31(33) (2015) 9214-9218.

[40] J. Baur, M. Holzinger, C. Gondran, S. Cosnier, Immobilization of biotinylated biomolecules onto electropolymerized poly(pyrrole-nitrilotriacetic acid)-Cu2+ film, Electrochemistry Communications 12(10) (2010) 1287-1290.

[41] J. Baur, C. Gondran, M. Holzinger, E. Defrancq, H. Perrot, S. Cosnier, Label-Free Femtomolar Detection of Target DNA by Impedimetric DNA Sensor Based on Poly(pyrrolenitrilotriacetic acid) Film, Analytical Chemistry 82(3) (2010) 1066-1072.

[42] F. Giroud, K. Gorgy, C. Gondran, S. Cosnier, D.G. Pinacho, M.P. Marco, F.J. SanchezBaeza, Impedimetric Immunosensor Based on a Polypyrrole-Antibiotic Model Film for the Label-Free Picomolar Detection of Ciprofloxacin, Analytical Chemistry 81(20) (2009) 84058409.

[43] C. Gondran, M.P. Dubois, S. Fort, S. Cosnier, Electrogenerated poly(pyrrole-Iactosyl) and poly(pyrrole-3 '-sialyllactosyl) interfaces: toward the impedimetric detection of lectins, Frontiers in Chemistry 1 (2013).

[44] N. Haddour, S. Cosnier, C. Gondran, Electrogeneration of a poly(pyrrole)-NTA chelator film for a reversible oriented immobilization of histidine-tagged proteins, Journal of the American Chemical Society 127(16) (2005) 5752-5753.

[45] I. Kazane, K. Gorgy, C. Gondran, N. Spinelli, A. Zazoua, E. Defrancq, S. Cosnier, Highly Sensitive Bisphenol-A Electrochemical Aptasensor Based on Poly(PyrroleNitrilotriacetic Acid)-Aptamer, Analytical Chemistry 88(14) (2016) 7268-7273.

[46] H. Xu, K. Gorgy, C. Gondran, A. Le Goff, N. Spinelli, C. Lopez, E. Defrancq, S. Cosnier, Label-free impedimetric thrombin sensor based on poly(pyrrole-nitrilotriacetic acid)aptamer film, Biosensors \& Bioelectronics 41 (2013) 90-95.

[47] A. Guiseppi-Elie, Electroconductive hydrogels: Synthesis, characterization and biomedical applications, Biomaterials 31(10) (2010) 2701-2716.

[48] P. Novak, B. Rasch, W. Vielstich, Overoxidation of polypyrrole in propylene carbonate An in situ FTIR study, Journal of the Electrochemical Society 138(11) (1991) 3300-3304.

[49] D. Samanta, N. Hosseini-Nassab, R.N. Zare, Electroresponsive nanoparticles for drug delivery on demand, Nanoscale 8(17) (2016) 9310-9317.

[50] S. Sirivisoot, R. Pareta, T.J. Webster, Electrically controlled drug release from nanostructured polypyrrole coated on titanium, Nanotechnology 22(8) (2011).

[51] Y.F. Li, Effect of anion concentration on the kinetics of electrochemical polymerization of pyrrole, Journal of Electroanalytical Chemistry 433(1-2) (1997) 181-186. 


\section{ACCEPTED MANUSCRIPT}

Table 1: First synthesis : influence of the nature of the weak-acid anion. PPy films obtained by polarization at $0.78 \mathrm{~V} / \mathrm{SCE}$ for $600 \mathrm{~s}$ in $0.15 \mathrm{M}$ Py aqueous solution containing $0.2 \mathrm{M}$ of weak-acid anion $+10^{-3} \mathrm{M}$ perchlorate or containing $0.2 \mathrm{M}$ perchlorate (no weak-acid anion).

\begin{tabular}{|c|c|c|c|c|}
\hline $\begin{array}{c}\text { Weak-acid } \\
\text { anion }\end{array}$ & Py solution pH & Anodic charge $(\mathrm{mC})$ & $\begin{array}{c}\text { Superhydrophilic } \\
\text { PPy film }{ }^{(1)}\end{array}$ & \\
\hline $\mathrm{HPO}_{4}{ }^{2-}$ & 8.9 & 9.7 & Yes & This work \\
\hline $\mathrm{CH}_{3} \mathrm{COO}^{-}$ & 8.3 & 5.9 & Yes & This work \\
\hline $\mathrm{CO}_{3}{ }^{2-}$ & 11.1 & 2.8 & Yes & This work \\
\hline $\mathrm{PO}_{4}{ }^{3-}$ & 12.6 & 1.15 & No & Ref. 26 \\
\hline $\mathrm{H}_{2} \mathrm{PO}_{4}^{-}$ & 4.8 & 350 & No & Ref. 26 \\
\hline \hline $\begin{array}{c}\mathrm{No}^{(2)} \\
\left(\left[\mathrm{ClO}_{4}{ }^{-}\right]=0.2 \mathrm{M}\right)\end{array}$ & $8.9^{(3)}$ & $500 \mathrm{mC}$ & No & Ref. 26 \\
\hline
\end{tabular}

${ }^{(1)}$ Nanostructured film ; ${ }^{(2)}$ Overoxidized PPy film ; ${ }^{(3)} \mathrm{pH}$ adjusted with $\mathrm{KOH}$ 


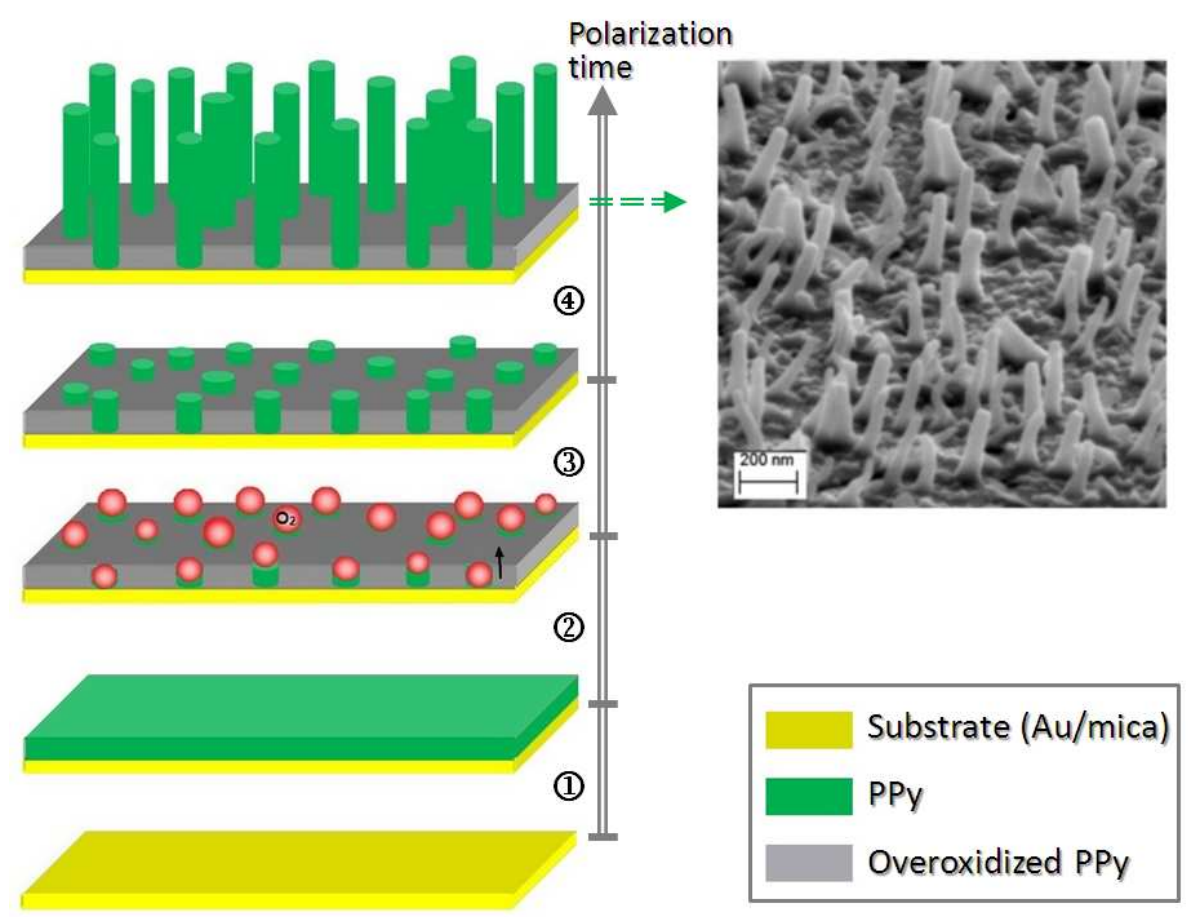

Figure 1. General mechanism of PPy nanowire electrogeneration. Left: Drawing showing the evolution of the polymer deposit with the anodic polarization time, in Py aqueous solution containing a high concentration of $\mathrm{K}_{2} \mathrm{HPO}_{4}$ and a low concentration of $\mathrm{LiClO}_{4}$. Right: SEM micrograph (side view, $60^{\circ}$ ) of PPy nanowires electrosynthesized at $0.75 \mathrm{~V} / \mathrm{SCE}$ for $200 \mathrm{~s}$ in $0.15 \mathrm{M} \mathrm{Py}+0.2 \mathrm{M} \mathrm{K}_{2} \mathrm{HPO}_{4}+10^{-3} \mathrm{M} \mathrm{LiClO}_{4}$ aqueous solution. Steps (1), (3), (4): Py oxidation ; step (2) : water oxidation leading to $\mathrm{OH}^{\bullet}$ and $\mathrm{O}_{2}$ formation. $\mathrm{O}_{2}$ locally protect the PPy film against the action of $\mathrm{OH}^{\bullet}$ which overoxidizes PPy. Steps (1), (2), (3) last around a few seconds. 

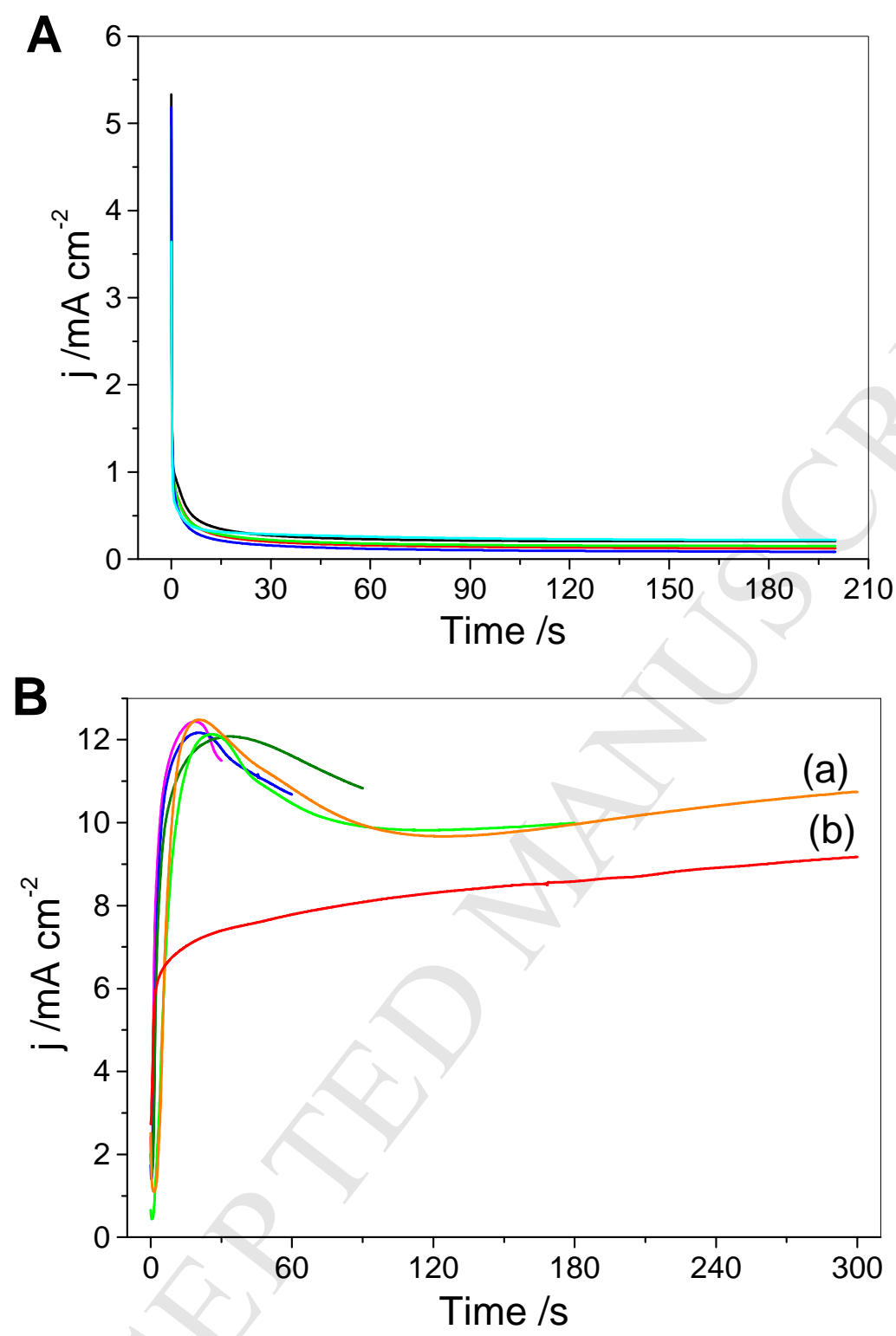

Figure 2. PPy electrosynthesis under potentiostatic conditions. Current density vs. time at a Pt electrode polarized at $0.75 \mathrm{~V} / \mathrm{SCE}$ in $0.15 \mathrm{M} \mathrm{Py}+0.2 \mathrm{M} \mathrm{K}_{2} \mathrm{HPO}_{4}+10^{-3} \mathrm{M} \mathrm{LiClO}_{4}$ (A) and then in $0.15 \mathrm{M} \mathrm{Py}+0.2 \mathrm{M} \mathrm{LiClO}_{4}$ (B curves (a)). B curve (b) bare Pt electrode polarized at $0.75 \mathrm{~V} / \mathrm{SCE}$ in $0.15 \mathrm{M} \mathrm{Py}+0.2 \mathrm{M} \mathrm{LiClO}_{4}$. In all cases, the surface used to calculate $\mathrm{J}$ is 0.07 $\mathrm{cm}^{2}$. 


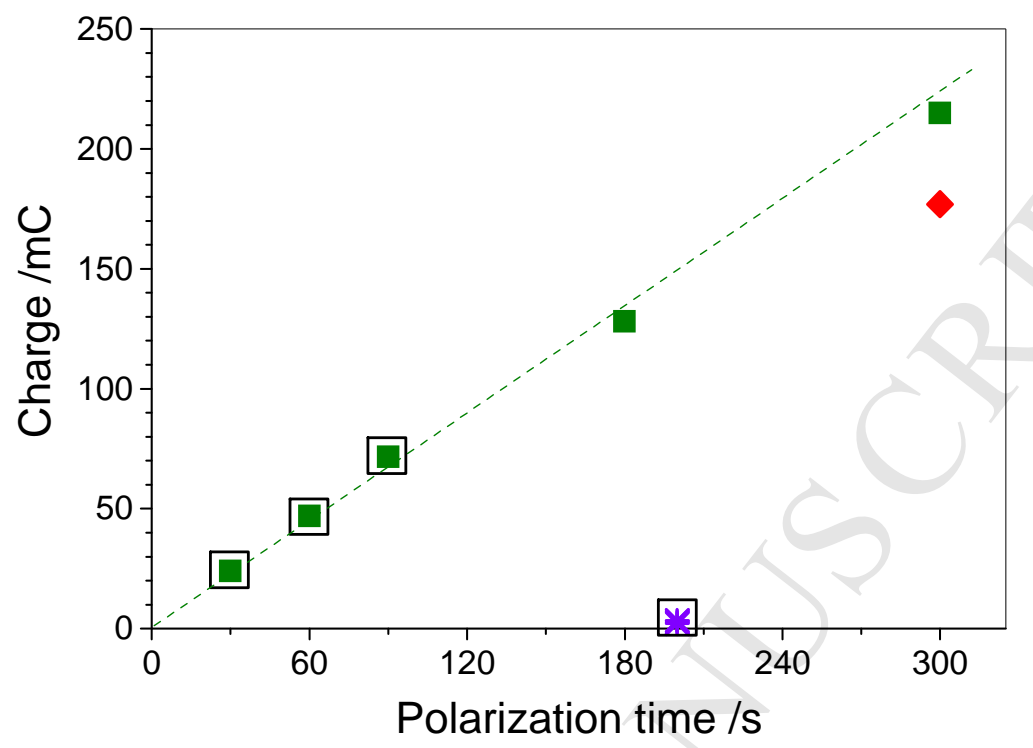

Figure 3. Anodic charge vs. polarization time, (*) first syntheses in $0.15 \mathrm{M} \mathrm{Py}+0.2 \mathrm{M}$ $\mathrm{K}_{2} \mathrm{HPO}_{4}+10^{-3} \mathrm{M} \mathrm{LiClO}_{4}($ the $\mathrm{j}(\mathrm{t})$ curves are shown in Fig. $2 \mathrm{~A} ; \mathrm{Q} \approx 1 \mathrm{mC}$ ) ; $(\mathbf{\square})$ second syntheses in $0.15 \mathrm{M} \mathrm{Py}+0.2 \mathrm{M} \mathrm{LiClO}_{4}$ (curves (a) in Fig. 2B) ; ( ) synthesis in 0.15 M Py + $0.2 \mathrm{M} \mathrm{LiClO}_{4}$ (curve (b) in Fig. 2B) (at a bare Pt electrode). The black open squares indicate the superhydrophilic PPy films i.e. the nanostructured films. 

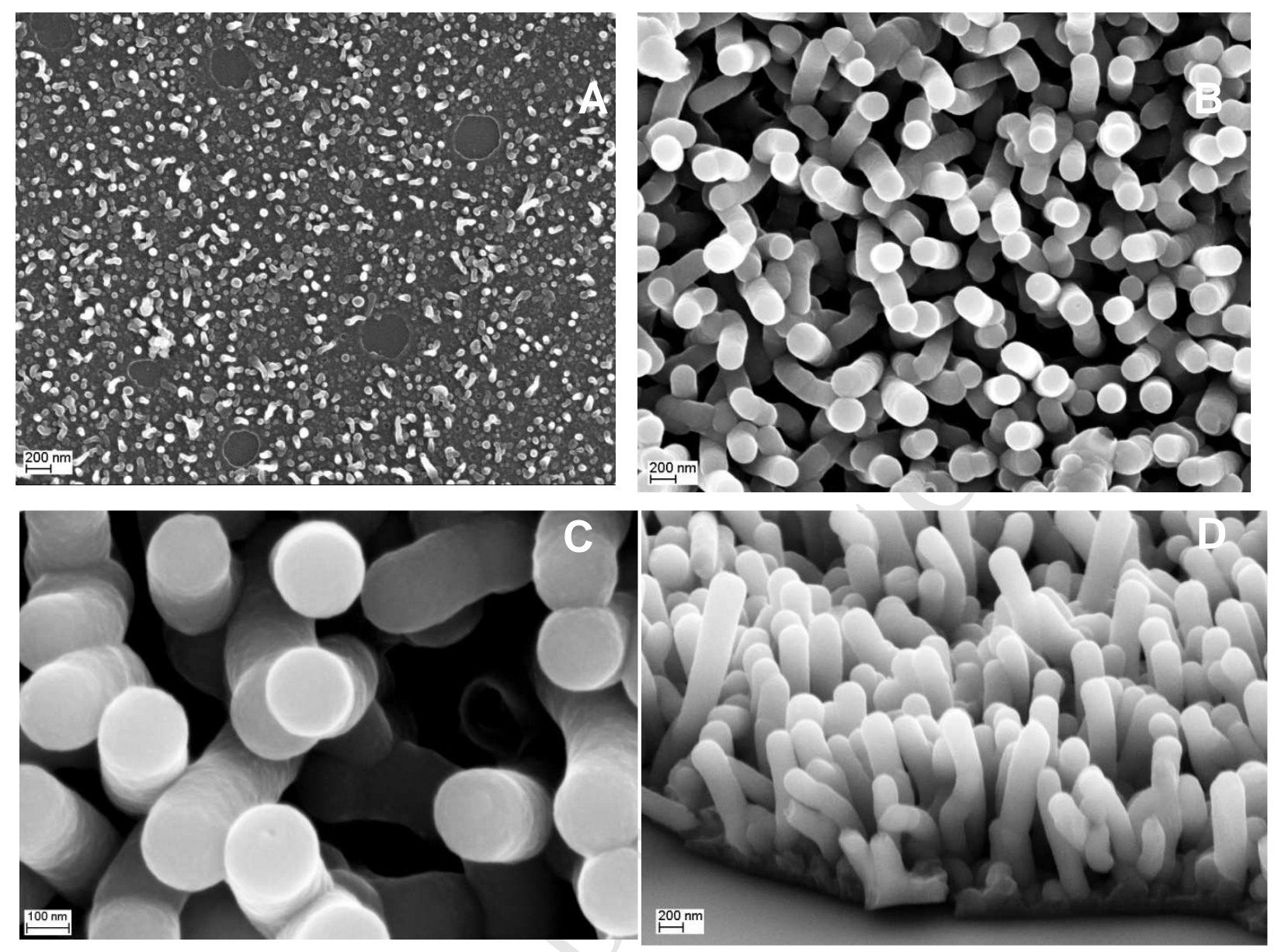

Figure 4. SEM micrographs of PPy. A) after a first synthesis at $0.75 \mathrm{~V} / \mathrm{SCE}$ for $600 \mathrm{~s}$ in 0.15 $\mathrm{M} \mathrm{Py}+0.2 \mathrm{M} \mathrm{K}_{2} \mathrm{HPO}_{4}+10^{-3} \mathrm{M} \mathrm{LiClO}_{4}$ aqueous solution. B-D) after a second synthesis at $0.75 \mathrm{~V} / \mathrm{SCE}$ for $50 \mathrm{~s}$ in $0.15 \mathrm{M} \mathrm{Py}+0.2 \mathrm{M} \mathrm{LiClO}_{4}$ aqueous solution. A,B,C top view, D side view $\left(60^{\circ}\right)$. Scale bar: $200 \mathrm{~nm}(\mathrm{~A}),(\mathrm{B}),(\mathrm{D}) ; 100 \mathrm{~nm}(\mathrm{C})$. 

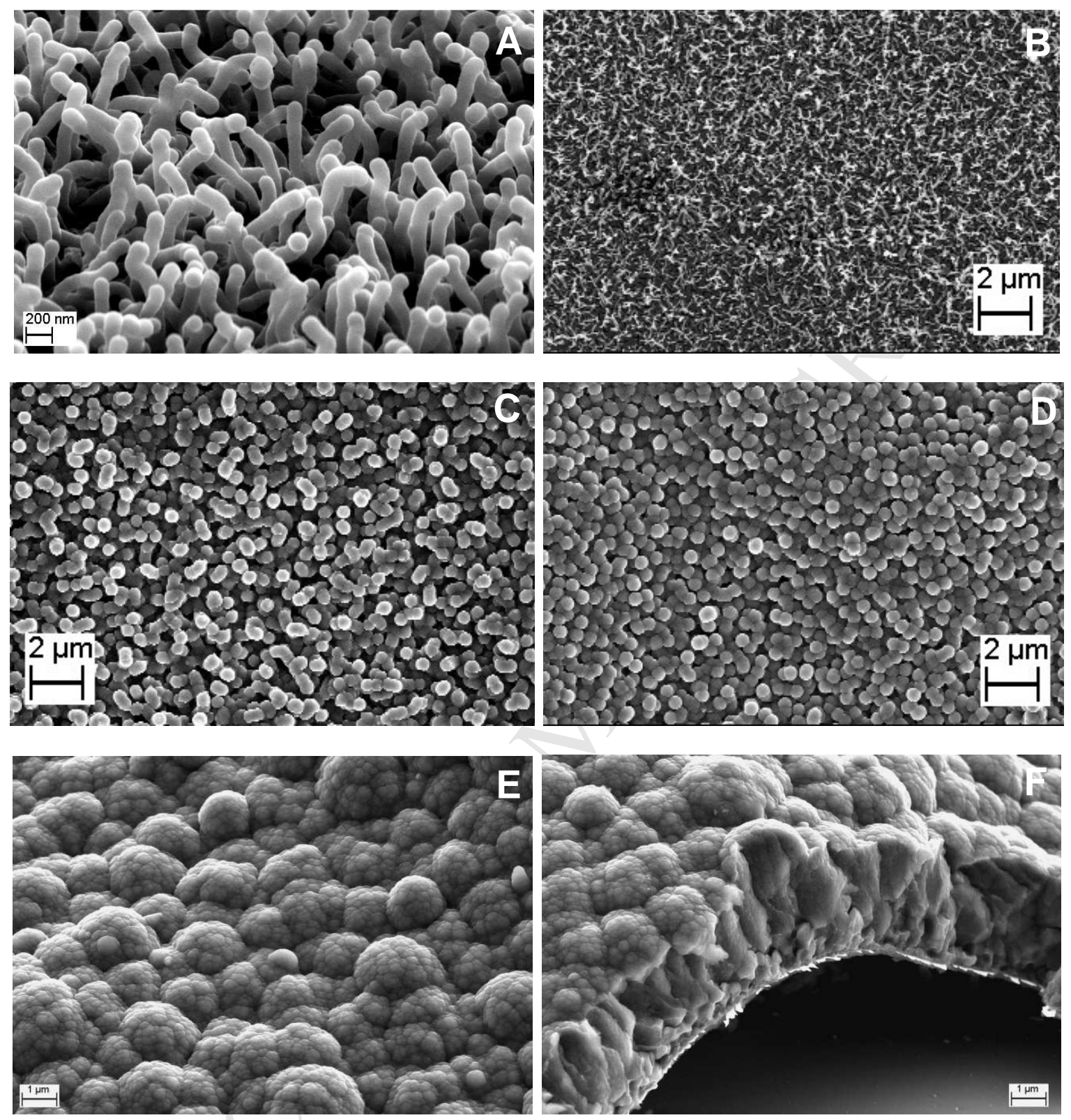

Figure 5. SEM micrographs of PPy films electrogenerated at $0.75 \mathrm{~V} / \mathrm{SCE}$ in two steps. First step was performed in $0.15 \mathrm{M} \mathrm{Py}+0.2 \mathrm{M} \mathrm{K}_{2} \mathrm{HPO}_{4}+10^{-3} \mathrm{M} \mathrm{LiClO}_{4}$ solution for $200 \mathrm{~s}$; second step in $0.15 \mathrm{M} \mathrm{Py}+0.2 \mathrm{M} \mathrm{LiClO}_{4}$ solution for (A,B) $30 \mathrm{~s}$, (C) $60 \mathrm{~s}$, (D) $90 \mathrm{~s},(\mathrm{E}, \mathrm{F}) 300$ s. Scale bars: (A) $200 \mathrm{~nm},(\mathrm{~B}-\mathrm{D}) 2 \mu \mathrm{m},(\mathrm{E}, \mathrm{F}) 1 \mu \mathrm{m}$. 


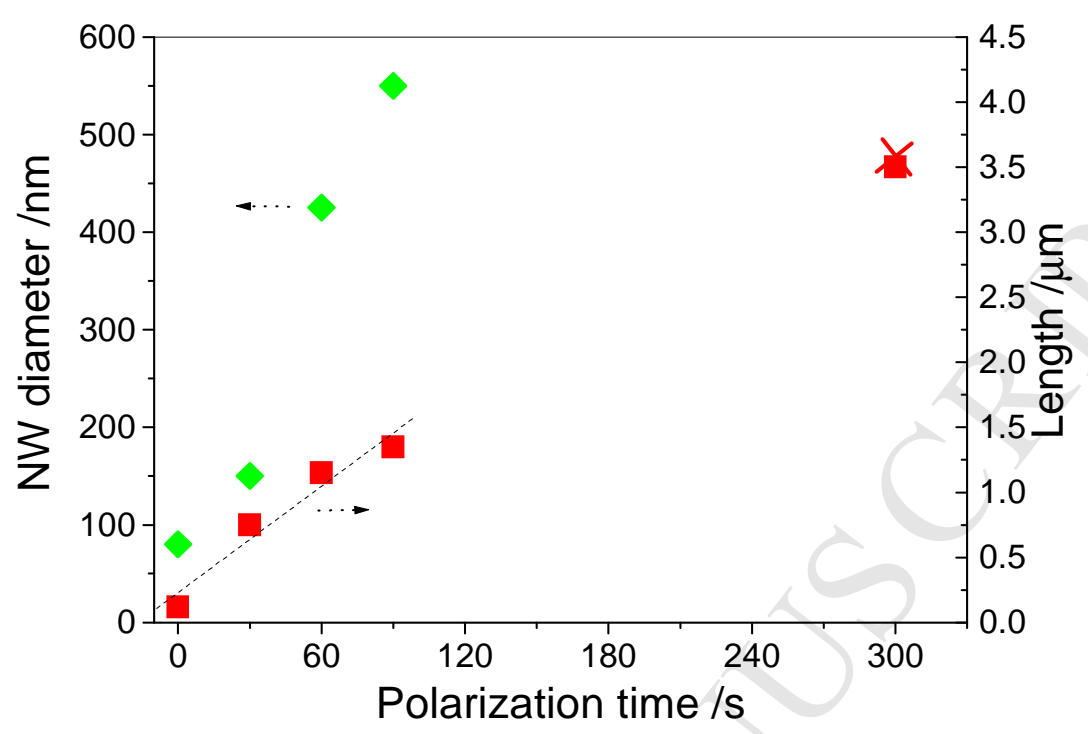

Figure 6. PPy nanowire (NW) characteristics after the second synthesis at $0.75 \mathrm{~V} / \mathrm{SCE}$ in $0.15 \mathrm{M} \mathrm{Py}+0.2 \mathrm{LiClO}_{4}$ at a NW-PPy/Pt electrode, the NW-PPy film being formed at 0.75 V/SCE for $200 \mathrm{~s}$ in $0.15 \mathrm{M} \mathrm{Py}+0.2 \mathrm{M} \mathrm{K}_{2} \mathrm{HPO}_{4}+10^{-3} \mathrm{M} \mathrm{LiClO}_{4}$. Left: $\mathrm{NW}$ diameter right: NW length (ם) or film thickness ( $)$ vs. polarization time. Some SEM micrographs are shown in Fig. 5. 

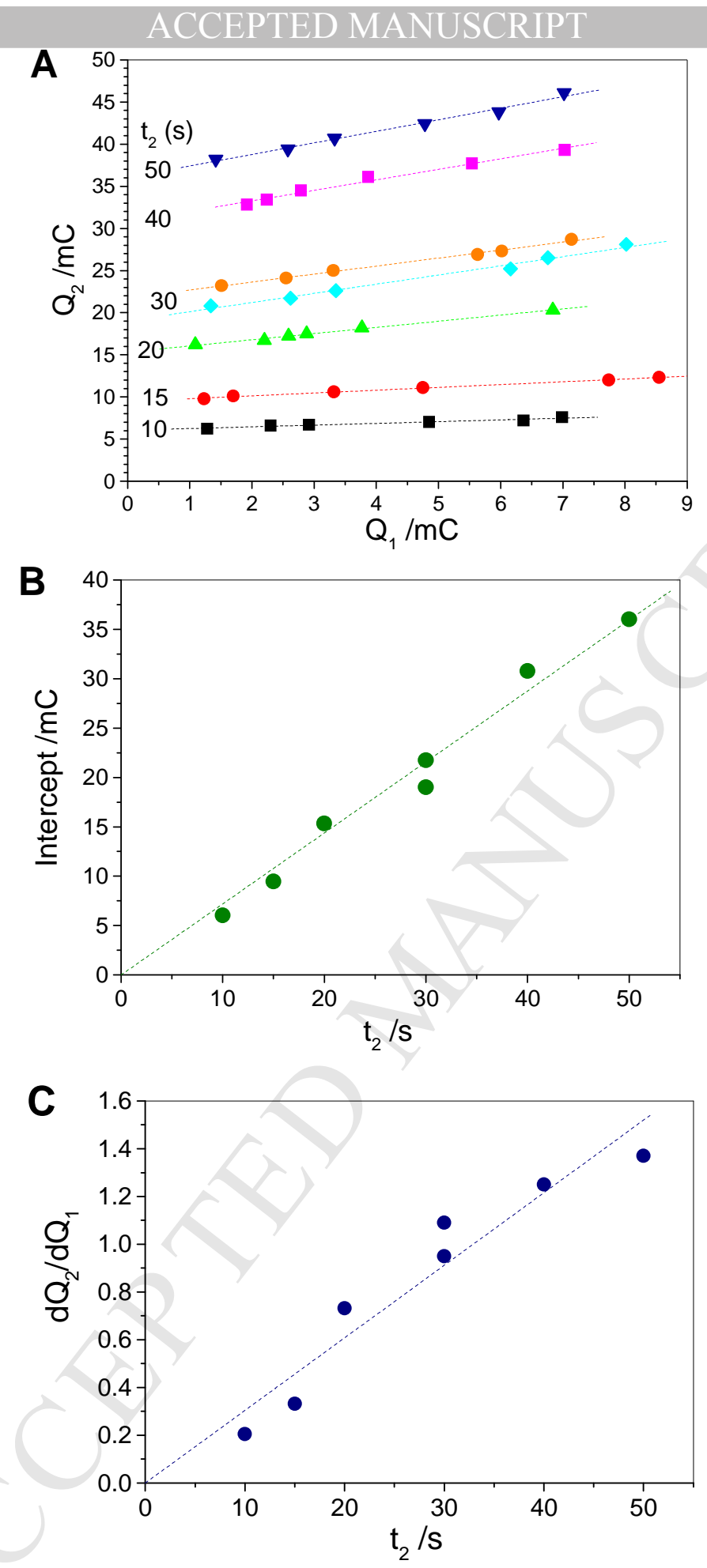

Figure 7. A) Anodic charge of the second synthesis performed during various times $\left(\mathrm{t}_{2}\right)$ in a classical Py solution $\left(0.2 \mathrm{M} \mathrm{LiClO}_{4}+0.15 \mathrm{M}\right.$ Py) vs. anodic charge of the first synthesis performed in $0.2 \mathrm{M} \mathrm{K}_{2} \mathrm{HPO}_{4}+10^{-3} \mathrm{M} \mathrm{LiClO}_{4}+0.15 \mathrm{M}$ Py solution, the polarization time of the first synthesis varying from 30 to $180 \mathrm{~s}$ (variation of the nanowire length). Electrode: $\mathrm{Pt}$ $\left(0.07 \mathrm{~cm}^{2}\right)$. Applied potential: 0.75 V/SCE. B and C) Y-intercept and slope of the relationship $\mathrm{Q}_{2}=\mathrm{f}\left(\mathrm{Q}_{1}\right)$ (graph $\left.\mathrm{A}\right)$ vs. the polarization time of the second synthesis, respectively. 


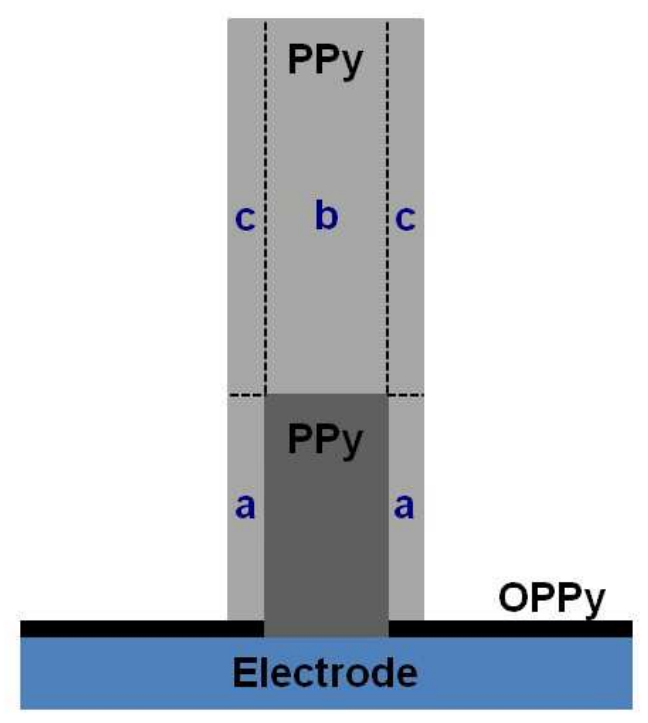

Figure 8. Drawing showing one PPy nanowire electrogenerated at $0.75 \mathrm{~V} / \mathrm{SCE}$ in two steps, the first synthesis being performed in $0.2 \mathrm{M} \mathrm{K}_{2} \mathrm{HPO}_{4}+10^{-3} \mathrm{M} \mathrm{LiClO}_{4}+0.15 \mathrm{M}$ Py solution and the second one in a 'classical' Py solution (0.2 $\mathrm{M} \mathrm{LiClO}_{4}+0.15 \mathrm{M}$ Py). Black: ultra-thin film of overoxidized PPy; dark grey: PPy nanowire after the first synthesis; light grey: PPy generated during the second synthesis. 